\title{
Community Outreach and Engagement Strategies to Address Breast Cancer Disparities
}

\author{
Lorna H. McNeill ${ }^{1}$ (D) - Ivan H. C. Wu ${ }^{1}$ - Dalnim Cho ${ }^{1} \cdot$ Qian Lu $^{1} \cdot$ Kamisha Escoto ${ }^{1}$ - Cassandra Harris ${ }^{1}$
}

Published online: 15 September 2020

(C) The Author(s) 2020

\begin{abstract}
Purpose of Review Breast cancer disproportionately affects racial/ethnic minority women compared with their non-Hispanic white counterparts. Community-based researchers have long sought to reduce breast cancer-related health disparities using the core principles of community outreach and engagement. The primary goal of this paper is to discuss community outreach and engagement (COE) strategies in the context of breast cancer disparities and discuss evidence-based applications of COE.

Recent Findings Evidence-based COE to address breast cancer disparities include patient navigation, co-development of community-based interventions, advisory boards, and patient boards. Recent strategies have included partnering with the Komen Tissue Bank, the development of culturally tailored expressive writing interventions, and the formation of community scientist and community mentorship programs.

Summary Partnering with the community across all stages of research can help eliminate breast cancer disparities. We find that community outreach and engagement can improve intervention efficacy, clinical trial retention, and community commitment. We hope that this paper will promote greater adoption of evidence-based COE strategies to help eliminate breast cancer disparities.
\end{abstract}

Keywords Breast cancer $\cdot$ Health disparities $\cdot$ Community outreach $\cdot$ Community engagement

\section{Introduction}

Breast cancer alone accounts for $30 \%$ of female cancers [1] and disproportionately affects specific groups. African American women have the highest rates of breast cancer mortality compared with all racial/ethnic groups and lower 5-year relative survival compared with white women [2]. Among Hispanic women, breast cancer is diagnosed at later stages [3] and is the leading cause of cancer-related death [4]. Notably, both African American and Hispanic women are more likely to develop triple-negative breast cancers compared with whites [5, 6]. A complex interaction of biological, sociopolitical, economic, and environmental factors

This article is part of the Topical Collection on Breast Cancer Disparities

Lorna H. McNeill

lmcneill@mdanderson.org

1 Department of Health Disparities Research, University of Texas MD Anderson Cancer Center, 1400 Pressler St.,

Houston, TX 77030, USA contributes to these disparities. Thus, eliminating breast cancer disparities are a significant public health concern.

It is well-understood that the hope of reducing breast cancer disparities requires an understanding of what is happening in affected communities through engagement of key stakeholders and community members who are dedicated to improving the health of their communities. The principles of community outreach and engagement are vital to conducting successful research with underrepresented communities. Community engagement is defined as mutually beneficial actions or values that promote shared respect, authenticity, and power sharing between researchers and community members [7-9]. This type of approach allows for bi-directional knowledge sharing that not only aims to incorporate community voices throughout the research process but also allows for researchers to engage in self-learning [10]. In contrast to the bi-directionality of community engagement, community outreach is the strategic coordination of multiple stakeholders to locate, contact, and recruit difficult to reach community members to engage in public health related activities. Community outreach often requires the coordination of multiple stakeholders such as community health workers, health educators, leaders of community organizations, and academics. 
Communities impacted by breast cancer must be fully engaged in research, education, and programmatic/policy efforts to eliminate breast cancer disparities. Breast cancer research has employed these principles in various ways. The purpose of the current paper is to highlight the importance of community engagement and outreach in reducing breast cancer-related health disparities and discuss evidence-based community engagement and outreach strategies such as patient navigation, community feedback to inform interventions, and community and patient advisory boards that have been effectively used in efforts to reduce cancer-related health disparities. We conclude with novel community outreach and engagement efforts being currently implemented across the country.

\section{Evidence-Based Community Outreach and Engagement Strategies for Breast Cancer Disparities}

Patient Navigation Since Dr. Freeman established the first patient navigation program at Harlem Hospital Center in New York City for underserved women (racial/ethnic minorities, poor, uninsured) in early 1990s [11], the program's remarkable success in enhancing breast cancer outcomes (e.g., improvement in early-stage breast cancer detection and survival) [12] launched patient navigation as a promising way to reduce breast cancer disparities. Patient navigators are often lay community members seeking to identify and reduce patient barriers encountered in seeking diagnosis and treatment $[11,13]$. They facilitate healthcare access and quality for underserved populations through advocacy, care coordination, trust building, and empowerment within the communities they serve [14]. For example, patient navigators assist in financial and insurance-related issues, coordinate appointments and care among multiple cancer providers, and train patients to self-advocate within the healthcare system [15].

To date, studies have consistently demonstrated that patient navigation can effectively enhance certain breast cancerrelated screening, diagnostic, and treatment initiation outcomes. For example, patient navigation has been shown to increase breast cancer screening uptake [16, 17], decrease delays in breast cancer diagnosis [17-19], and increase early treatment initiation [17] among underserved women. To further reduce breast cancer disparities, future directions of patient navigation should focus on breast cancer survivorship, and end-of-life care is much warranted.

Intervention Development "Whatever the question, the answer is in the community" [20]. Community engagement is vital in developing and implementing effective interventions to reduce breast cancer disparities. Evidence-based interventions show better outcomes when the intervention is adapted and tailored to the community through partnerships that include both researchers and practitioners [21, 22]. Frameworks have been developed to guide how researchers can contextualize intervention components and research design through community members' lived realities. For example, based on IM Adapt [22] (adapted from Intervention Mapping [23]), Highfield and colleagues designed an intervention to improve mammography adherence for uninsured, African American women in a new practice setting using mobile mammography. Through a need assessment among local African American women, the researchers identified salient logistical, emotional, and cultural barriers to mammogram uptake such as insurance, cost, transportation, fear of the outcome, anticipated pain during the screening, and the belief that faith would protect them from cancer [24]. Then, these identified barriers were addressed in the intervention through various strategies including role modeling (e.g., quotations from women in the community regarding barriers), correcting misinformation, persuasion (by culturally congruent navigator), and planning with navigator to cope with logistical barriers. Community engagement strategies can be used for all intervention pathways including conception/planning, promotion, recruitment, implementation, retention, evaluation, outcome, and dissemination/capacity by engaging community members and stakeholders, which is key to achieve sustainability.

Advisory Boards/Patient Boards One of the most prominent examples of community engagement has been patient/ stakeholder and community advisory boards. Advisory boards are often used in community-based research as a mechanism to provide structure to the partnership and guide the research [25]. They are typically comprised of individuals that are as representative as possible to the target research community or population, with their expertise sought throughout the research process. Functions of advisory boards include brainstorming and identifying research questions; creating conceptual frameworks; advising on research study design, data collection and implementation; evaluating study materials; helping to disseminate information; and collaborating with investigators to advocate for policy change $[25,26]$. Advisory boards have been used broadly for community engagement across the breast cancer continuum. Typically, members are a mixture of cancer survivors, advocates, oncologists, community leaders, service providers, and professionals specific to the intervention. The Breast Cancer Prevention Trial, for example, formed a national patient advisory council composed of trial participants to provide advisement on the trial, share their experiences as participants, and provide patient education [27]. Advisory boards have been employed, for example, in the design of breast cancer decision aids for surgery [28] and radiation treatment [29], to develop interventions for stress management in newly diagnosed Latinas with breast cancer [30], to help inform a culturally sensitive video 
for Chinese women to promote mammography [31], and to inform survivorship care planning [32].

\section{Two Illustrative Case Studies}

Diversity by Design: Strategies to Engage Minority Communities in Biomedical Research Despite the congressional directive and NIH policy to include minorities and women in NIH-funded clinical research, biomedical research currently does not have adequate representation of diverse populations, particularly biobanking protocols. A group of Indiana University breast advocates sought to increase biobanking for breast cancer and collected 750 blood samples at Komen's Race for the Cure in Indianapolis in 2005. While many healthy women were willing to donate their breast tissue, over the years, the percentage of minority donors was low. The Komen Tissue Bank is part of Indiana University, Indianapolis, Indiana. It is the only biobank in the world that collects healthy breast tissue for researchers around the world to use as normal controls in their breast cancer studies. In 2014, the Susan G. Komen Breast Cancer Foundation's Houston affiliate leads the planning of a Komen Tissue Bank community event to expand exposure of this issue beyond the Midwest and increase the amount of healthy tissue from diverse women. The challenge was to collect breast tissue from 200 diverse women in the Greater Houston area.

Recognizing the importance of engaging the community, i.e., racial and ethnic minority women, in this process, Komen partnered with the Center for Community-engaged Translational Research (CCETR) at MD Anderson Cancer Center-which brings researchers and communities together to create long-term solutions to prevent cancer and improve the health of communities - and with strong partners in the Houston faith community. To begin, we held community information sessions with church leaders to get their input on how to implement the event in Houston. This group hosted committee meetings, guided the planning, and identified others to bring to the table to ensure success. Suggested strategies included a focus on awareness and education, addressing fears, including church auxiliary ministries in this combined effort and being a constant presence at every church event/meeting (Worship, Bible Studies, Ministry Meetings). The committee developed promotional materials and provided guidance to the communications teams at the Komen Tissue Bank regarding marketing to African American women, including collaboration with a local celebrity survivor and talk show appearances. The Komen Tissue Bank received an overwhelming response from diverse women in the Greater Houston area. They achieved their goal of collecting 200 breast tissue samples from diverse healthy women, strengthened relationships with community leaders and organizations, established new community relationships, and paved the way for biobanking research in the future.

Expressive Writing to Improve Quality of Life Breast cancer incidence rates are increasing among Asian American women [33, 34], and Asian immigrant breast cancer survivors have a higher mortality rate than their US-born counterparts [35]. Asian Americans are less likely to be enrolled in research compared with other ethnic groups [36]. Common barriers to participating in research include mistrust of institutions [37], the fears of being a "guinea pig" [38], a lack of exposure to research studies [39], concerns about time commitment [40], and limited English proficiency [38]. Overcoming these barriers is extremely important in eliminating health disparities. To illustrate relevant strategies in engaging community members, we provide a case study of implementing a randomized controlled trial among Chinese immigrant breast cancer survivors using a community-based participatory research (CBPR) approach [41] to implementing the study. The study was designed and implemented in collaboration with Herald Cancer Association, a non-profit organization serving the Chinese immigrant population in Southern California.

Chinese culture is a "relational culture" [42]; therefore, we took a relational approach to engage community members. We approached recruitment as an opportunity to build relationships with potential participants. Community research staff acted as relationship builders and recruiters, reducing the power differential that often exists between academic researchers and research participants, particularly for an immigrant sample with limited English ability [43]. Recruiters' first priority was to establish an environment in which individuals felt personally cared for. Prior to any mention of the study, recruiters took time to inquire about the individual's life and listen to her. This approach was important as it helped researchers to build trust and understand potential barriers to participation. Throughout the process, recruiters focused on relationship building, understanding difficulties and challenges potential participants were going through, and helping them to overcome challenges for participation. As a result, the study had a successful $81 \%$ enrollment rate. We ensured study materials were culturally appropriate and included native Chinese speakers from multiple Chinese-speaking countries (China, Taiwan, Hong Kong) and represented proficiency with multiple dialects (e.g., Mandarin, Cantonese) and character forms (i.e., traditional, simplified). Documents such as recruitment scripts and interview guides that were more conversational in nature were originally written in Chinese to 
maintain native phrasing and sentence structures. All materials were piloted with a focus group of female Chinese breast cancer survivors recruited through a local nonprofit organization serving Chinese cancer patients.

\section{New Community Outreach and Engagement Strategies}

Although most US cancer centers have long focused on impacting the health of the population in their catchment areas, outside of cancer treatment, including prevention and education efforts, the NCI continues to reinforce the importance of this mission and obligation of cancer centers to engage diverse populations within their catchment in cancer center research. Community outreach and engagement (COE) offices seek to reduce cancer burden in their catchment area through education, outreach, and engagement. Novel community engagement strategies are being implemented in COE offices across the country.

Community Scientist Program Resources and infrastructure to support community engagement are necessary, such as a comprehensive and diverse network of community partners (breast service providers, community clinics, advocacy organizations, community health professionals). Creating and maintaining such networks are extraordinarily labor-intensive and time-consuming, with most researchers not having the time for such investment. One approach facilitates a coordinated encounter between researchers and communities that stimulate communication, particularly about research design and development. Termed "community scientist" at MD Anderson, or "engagement studios" at Vanderbilt, it is an approach that stimulates bi-directional communication between researchers and community members [44, 45]. The Community Scientist Program is a network of community members representing vulnerable population groups who meet monthly with researchers to consult on the design, implementation, and dissemination of their research. Community members, who are already natural advocates for issues within their community, receive training on human subjects, biomedical research, and methods of community engagement to prepare them to consult with researchers. Community scientists serve as a sounding board to ensure that research addresses local patient and community stakeholder interests, provide advice on the development of culturally appropriate studies and recruitment strategies, provide input on research questions, and study designs. Researchers benefit from access to community experts from various backgrounds, receipt of feedback at different stages of the research process, and expert consultation for participant recruitment. Such programs have been well received by both researchers and communities, with evaluations indicating that feedback enhances research quality and community members feeling the program being worth their time $[44,46]$. Programs with goals similar to community scientist have unique advantages over traditional methods of engagement. Community members are engaged on an as-needed basis and thus do not have to commit their time to the ongoing meetings that may be required with service to an advisory board [30]. Community scientist training includes advocacy and empowers community members to feel confident sharing their perspectives. This counters potential weaknesses in advisory boards as community members may not have an experience working with researchers and feel uncomfortable sharing their thoughts and opinions [25, 29].

Community Mentors Mentors are an integral part of training and education in research. Mentors share new knowledge and skills in a specific area and provide guidance and support to ultimately help trainees achieve independence. Mentorship has been noted as the single most important indicator of future success [47]. While no one would question the importance of research mentors in academic research, the importance of community mentors, and their role they play in research mentorship team, is often overlooked, likely because few research teams include community mentors. Community mentors are people who understand and/or know the lived experiences of the people we are trying to serve through research; they connect us to communities directly affected by our research. Known as Patient Advocates, or community advisory board members, community mentors should be an integral part of research teams seeking to eliminate breast cancer disparities. Similar to research mentors that teach research fundamentals and are context experts, community mentors share knowledge about how to partner with breast cancer communities and those at-risk, may provide access to those affected by breast cancer, and provide greater context to the importance and relevance of their research to the elimination of breast cancer disparities. As part of the research team, they should be included in research team meetings and can evaluate research proposals and studies for community relevance. Community mentors should be seen as equal to research mentors, because they bring complementary, unique expertise to the research experience. Every breast cancer disparities training program should consider the mandatory inclusion of community mentors as part of the research team.

Clinical Trial Patient Navigation Increasing clinical trial participation among racial and ethnic minorities is upmost concern [48]. While racial and ethnic minorities indicate willingness to participation in clinical trials, their 
participation is still low relative to whites. In breast cancer research, where female participation is rather robust, compared with other cancer sites, i.e., colorectal cancer, racial and ethnic minority participation is still lower than whites [49]. Innovation in community engagement for clinical trial recruitment has focused on the role of clinical trial patient navigators. Similar to patient navigation as described earlier, clinical trial navigators help to increase knowledge and awareness about clinical trials, facilitate access to and potential enrollment to a clinical trial, and reduce barriers to retention and study completion by addressing concerns after enrollment [50]. Recent studies show that their inclusion as part of the clinical trial team increases trial participation in cancer clinical trials. Fouad and colleagues at the University of Alabama at Birmingham employed clinical trial navigators as a mechanism to increase recruitment and retention of African American to clinical trials and saw African American clinical trial participation increase from 9 to $16 \%$ during the study period (2007 to 2014) [51, 52]. Now, many cancer centers are adopting clinical trial navigation, in addition to traditional clinical patient navigation, as innovative ways to address barriers to clinical trial participation, build trust, and increase enrollment of racial and ethnic minorities.

\section{Conclusion}

Racial/ethnic minority women bear disproportionate burden of higher breast cancer prevalence, mortality, and delay for treatment. Community outreach and engagement are effective strategies to not only increase the low participation rates of racial/ ethnic minority women in breast cancer clinical trials but also improve efficacy and relevance of community-based interventions. Our research groups have long-standing partnerships with local communities who we involve in the development of our recruitment and implementation strategies, research design, and dissemination. In dialog with these partnerships, new and innovative strategies we are currently developing or implementing seek to enhance bi-directional communication between the community-researcher relationship (e.g., Community Scientist Program), train the next generation of breast cancer health disparities scholars (e.g., community mentors program), and increase racial/ethnic minority participation in clinical trials (e.g., clinical trial patient navigation program). We hope that by sharing our efforts, researchers will be encouraged to conduct greater community outreach and engagement to eliminate breast cancer disparities.

\section{Compliance with Ethical Standards}

Conflict of Interest The authors declare that they have no conflict of interest.
Human and Animal Rights and Informed Consent This article does not contain any studies with human or animal subjects performed by any of the authors.

Open Access This article is licensed under a Creative Commons Attribution 4.0 International License, which permits use, sharing, adaptation, distribution and reproduction in any medium or format, as long as you give appropriate credit to the original author(s) and the source, provide a link to the Creative Commons licence, and indicate if changes were made. The images or other third party material in this article are included in the article's Creative Commons licence, unless indicated otherwise in a credit line to the material. If material is not included in the article's Creative Commons licence and your intended use is not permitted by statutory regulation or exceeds the permitted use, you will need to obtain permission directly from the copyright holder. To view a copy of this licence, visit http://creativecommons.org/licenses/by/4.0/.

\section{References}

1. Siegel RL, Miller KD, Jemal A. Cancer statistics, 2020. CA Cancer J Clin. 2020;70(1):7-30. https://doi.org/10.3322/caac.21590.

2. American Cancer Society. Cancer Facts \& Figures for African Americans 2019-2021. Atlanta. GA: American Cancer Society. p. 2019.

3. Smith EC, Ziogas A, Anton-Culver H. Delay in surgical treatment and survival after breast cancer diagnosis in young women by race/ethnicity. JAMA Surg. 2013;148(6):516-23. https://doi.org/ 10.1001/jamasurg.2013.1680.

4. American Cancer Society. Cancer Facts \& Figures for Hispancis/ Latinos 2018-2020. Atlanta: American Cancer Society. p. 2018.

5. Dietze EC, Chavez TA, Seewaldt VL. Obesity and triple-negative breast Cancer: disparities, controversies, and biology. Am J Pathol. 2018;188(2):280-90. https://doi.org/10.1016/j.ajpath.2017.09.018.

6. Scott LC, Mobley LR, Kuo T-M, Il'yasova D. Update on triplenegative breast cancer disparities for the United States: a population-based study from the United States cancer statistics database, 2010 through 2014. Cancer. 2019;125(19):3412-7. https:// doi.org/10.1002/cncr.32207.

7. Minkler M, Wallerstein N. Community-based participatory research for health : from process to outcomes. John Wiley \& Sons, Incorporated: Hoboken; 2008.

8. Israel BA, Eng E, Schulz AJ, Parker EA, Satcher D, Israel BA, et al. Methods in community-based participatory research for health: Jossey-Bass; 2005.

9. Jones L, Wells K. Strategies for academic and clinician engagement in community-participatory partnered research. JAMA. 2007;297(4):407-10. https://doi.org/10.1001/jama.297.4.407.

10. Freire P. Pedagogy of the oppressed. Continuum: Pedagogía del oprimido.English; 1970.

11. Freeman HP. Patient navigation: a community centered approach to reducing cancer mortality. J Cancer Educ. 2006;21(1 Suppl):S11-4. https://doi.org/10.1207/s15430154jce2101s 4.

12. Oluwole SF, Ali AO, Adu A, Blane BP, Barlow B, Oropeza R, et al. Impact of a cancer screening program on breast cancer stage at diagnosis in a medically underserved urban community. J Am Coll Surg. 2003;196(2):180-8. https://doi.org/10.1016/s10727515(02)01765-9.

13. Freund KM. Patient navigation: the promise to reduce health disparities. J Gen Intern Med. 2011;26(2):110-2. https://doi.org/10. 1007/s11606-010-1593-5.

14. Natale-Pereira A, Enard KR, Nevarez L, Jones LA. The role of patient navigators in eliminating health disparities. Cancer. 2011;117(15 Suppl):3543-52. https://doi.org/10.1002/cncr.26264. 
15. Freund KM, Battaglia TA, Calhoun E, Dudley DJ, Fiscella K, Paskett E, et al. National Cancer Institute patient navigation research program: methods, protocol, and measures. Cancer. 2008;113(12):3391-9. https://doi.org/10.1002/cncr.23960.

16. Marshall JK, Mbah OM, Ford JG, Phelan-Emrick D, Ahmed S, Bone L, et al. Effect of patient navigation on breast cancer screening among African American Medicare beneficiaries: a randomized controlled trial. J Gen Intern Med. 2016;31(1):68-76. https://doi. org/10.1007/s11606-015-3484-2.

17. Krok-Schoen JL, Oliveri JM, Paskett ED. Cancer care delivery andwomen's health: the role of patient navigation. Front Oncol. 2016;6:2. https://doi.org/10.3389/fonc.2016.00002.

18. Hoffman HJ, LaVerda NL, Young HA, Levine PH, Alexander LM, Brem R, et al. Patient navigation significantly reduces delays in breast cancer diagnosis in the District of Columbia. Cancer Epidemiol Biomark Prev. 2012;21(10):1655-63. https://doi.org/ 10.1158/1055-9965.Epi-12-0479.

19. Battaglia TA, Darnell JS, Ko N, Snyder F, Paskett ED, Wells KJ, et al. The impact of patient navigation on the delivery of diagnostic breast cancer care in the National Patient Navigation Research Program: a prospective meta-analysis. Breast Cancer Res Treat. 2016;158(3):523-34. https://doi.org/10.1007/s10549-016-3887-8.

20. Allers K. Powered by community. 2014. http://www. kimberlysealsallers.com/powered-by-community-event.

21. Highfield L, Hartman MA, Mullen PD, Rodriguez SA, Fernandez ME, Bartholomew LK. Intervention mapping to adapt evidencebased interventions for use in practice: increasing mammography among African American women. Biomed Res Int. 2015;2015: 160103-11. https://doi.org/10.1155/2015/160103.

22. Meade CD, Menard J, Thervil C, Rivera M. Addressing cancer disparities through community engagement: improving breast health among Haitian women. Oncol Nurs Forum. 2009;36(6): 716-22. https://doi.org/10.1188/09.ONF.716-722.

23. Bartholomew Eldredge LK, Markham CM, Ruiter RAC, Fernández ME, Kok G, Parcel GS. Planning health promotion programs: an intervention mapping approach. 2016.

24. Highfield L, Bartholomew LK, Hartman MA, Ford MM, Balihe P. Grounding evidence-based approaches to cancer prevention in the community: a case study of mammography barriers in underserved African American women. Health Promot Pract. 2014;15(6):90414. https://doi.org/10.1177/1524839914534685.

25. Newman SD, Andrews JO, Magwood GS, Jenkins C, Cox MJ, Williamson DC. Community advisory boards in communitybased participatory research: a synthesis of best processes. Prev Chronic Dis. 2011;8(3):A70.

26. O'Haire C, McPheeters M, Nakamoto E, LaBrant L, Most C, Lee $\mathrm{K}$, et al. Engaging stakeholders to identify and prioritize future research needs. Agency for Healthcare Research and Quality: Rockville, MD; 2011.

27. Psillidis L, Flach J, Padberg RM. Participants strengthen clinical trial research: the vital role of participant advisors in the Breast Cancer Prevention Trial. J Women's Health. 1997;6(2):227-32. https://doi.org/10.1089/jwh.1997.6.227.

28. Durand M-A, Song J, Yen RW, Sepucha K, Politi MC, Dhage S et al. Adapting the breast cancer surgery decision quality instrument for lower socioeconomic status: improving readability, acceptability, and relevance. MDM Policy Pract. 2018;3(2). https://doi.org/ $10.1177 / 2381468318811839$.

29. Kelly G, Wang S-Y, Lucas G, Fraenkel L, Gross CP. Facilitating meaningful engagement on community advisory committees in patient-centered outcome research. Prog Commun Health Partnerships: Res Educ Act. 2017;11(3):243-51. https://doi.org/ 10.1353/cpr.2017.0029.

30. Nápoles AM, Santoyo-Olsson J, Ortiz C, Gregorich S, Lee HE, Duron Y, et al. Randomized controlled trial of Nuevo Amanecer: a peer-delivered stress management intervention for Spanish- speaking Latinas with breast cancer. Clin Trials. 2014;11(2):230 8. https://doi.org/10.1177/1740774514521906.

31. Wang JH, Liang W, Schwartz MD, Lee MM, Kreling B, Mandelblatt JS. Development and evaluation of a culturally tailored educational video: changing breast cancer-related behaviors in Chinese women. Health Educ Behav. 2008;35(6):806-20. https://doi.org/10.1177/1090198106296768.

32. Garcia SF, Kircher SM, Oden M, Veneruso A, JM MK, Pearman T, et al. Survivorship care planning in a comprehensive cancer center using an implementation framework. J Commun Support Oncol. 2016;14(5):192. https://doi.org/10.12788/jcso.0255.

33. Gomez SL, Quach T, Horn-Ross PL, Pham JT, Cockburn M, Chang ET, et al. Hidden breast cancer disparities in Asian women: disaggregating incidence rates by ethnicity and migrant status. Am J Public Health. 2010;100(suppl 1(S1)):S125-S31. https://doi.org/ 10.2105/AJPH.2009.163931.

34. Torre LA, Sauer AMG, Chen MS, Kagawa-Singer M, Jemal A, Siegel RL. Cancer statistics for Asian Americans, Native Hawaiians, and Pacific Islanders, 2016: converging incidence in males and females. CA Cancer J Clin. 2016;66(3):182-202. https://doi.org/10.3322/caac.21335.

35. Gomez SL, Clarke CA, Shema SJ, Chang ET, Keegan THM, Glaser SL. Disparities in breast cancer survival among Asian women by ethnicity and immigrant status: a population-based study. Am J Public Health. 2010;100(5):861-9. https://doi.org/10.2105/AJPH. 2009.176651.

36. Ashing-Giwa K, Tapp C, Rosales M, McDowell K, Martin V, Santifer RH, et al. Peer-based models of supportive care: the impact of peer support groups in African American breast cancer survivors. Oncol Nurs Forum. 2012;39(6):585-91. https://doi.org/10.1188/ 12.ONF.585-591.

37. Giarelli E, Bruner D, Nguyen E, Basham S, Marathe P, Dao D, et al. Research participation among Asian American women at risk for cervical cancer: exploratory pilot of barriers and enhancers. $\mathrm{J}$ Immigr Minor Health. 2011;13(6):1055-68. https://doi.org/10. 1007/s10903-011-9461-x.

38. Nguyen TT, Somkin CP, Ma Y. Participation of Asian-American women in cancer chemoprevention research. Cancer. 2005;104(S12):3006-14. https://doi.org/10.1002/cncr.21519.

39. Han H-R, Kang J, Kim K, Ryu J, Kim M. Barriers to and strategies for recruiting Korean Americans for community-partnered health promotion research. J Immigr Minor Health. 2007;9(2):137-46. https://doi.org/10.1007/s10903-006-9022-x.

40. Maxwell A, Bastani R, Vida P, Warda U. Strategies to recruit and retain older Filipino-American immigrants for a cancer screening study. J Community Health. 2005;30(3):167-79. https://doi.org/10. 1007/s10900-004-1956-0.

41. Israel BA, Schulz AJ, Parker EA, Becker AB. Review of community-based research: assessing partnership approaches to improve public health. Annu Rev Public Health. 1998;19(1):173202. https://doi.org/10.1146/annurev.publhealth.19.1.173.

42. Yau OHM. Chinese cultural values: their dimensions and marketing implications. Eur J Mark. 1988;22(5):44-57. https://doi.org/10. 1108/EUM0000000005285.

43. Lu Q, Gallagher MW, Loh A, Young L. Expressive writing intervention improves quality of life among Chinese-American breast Cancer survivors: a randomized controlled trial. Ann Behav Med: A Publ Soc Behav Med. 2018;52(11):952-62. https://doi.org/10. 1093/abm/kax067.

44. Joosten AY, Israel LT, Williams AN, Boone RL, Schlundt GD, Mouton PC, et al. Community engagement studios: a structured approach to obtaining meaningful input from stakeholders to inform research. Acad Med. 2015;90(12):1646-50. https://doi.org/ 10.1097/ACM.0000000000000794.

45. Wilkins CH, Spofford M, Williams N, McKeever C, Allen S, Brown J, et al. Community representatives' involvement in clinical 
and translational science awardee activities. Clin Transl Sci. 2013;6(4):292-6. https://doi.org/10.1111/cts.12072.

46. Joosten YA, Israel TL, Head A, Vaughn Y, Villalta Gil V, Mouton $\mathrm{C}$, et al. Enhancing translational researchers' ability to collaborate with community stakeholders: lessons from the community engagement studio. J Clin Transl Sci. 2018;2(4):201-7. https://doi.org/10. 1017/cts.2018.323.

47. Sambunjak D, Straus SE, Marusic A. Mentoring in academic medicine: a systematic review. JAMA. 2006;296(9):1103-15. https:// doi.org/10.1001/jama.296.9.1103.

48. Polite BN, Adams-Campbell LL, Brawley OW, et al. Chartering the future of cancer health disparities research: a position statement from the American Association for Cancer Research, the American Cancer Society, the American Society of Clinical Oncology, and the National Cancer Institute. Cancer Res. 2017;67(5):353-61. https://doi.org/10.1158/0008-5472.
49. Murthy VH, Krumholz HM, Gross CP. Participation in cancer clinical trials: race-,sex-, and age-based disparities. JAMA. 2004;291(22):2720-6. https://doi.org/10.1001/jama.291.22.2720.

50. Paskett ED, Harrop JP, Wells KJ. Patient navigation: an update on the state of the science. CA Cancer J Clin. 2011;61(4):237-49. https://doi.org/10.3322/caac.20111.

51. Nipp RD, Hong K, Paskett ED. Overcoming barriers to clinical trial enrollment. Am Soc Clin Oncol Educ Book. 2019;39:105-14. https://doi.org/10.1200/dbk_243729.

52. Fouad MN, Acemgila, Bae $\overline{\mathrm{S}}$, et al. Patient navigation as a model to increase participation of African Americans in cancer clinical trials. J Oncol Pract. 2016;12:556-63. https://doi.org/10.1200/JOP.2015. 008946.

Publisher's Note Springer Nature remains neutral with regard to jurisdictional claims in published maps and institutional affiliations. 